\title{
RECURSO MANIFIESTAMENTE INFUNDADO COMO FILTRO DE BUENA FE: LA CASACIÓN CHILENA EN PERSPECTIVA COMPARADA
}

\section{MANIFESTLY ILL-FOUNDED APPEAL AS FILTER OF GOOD FAITH: CHILEAN CASSATION IN COMPARATIVE PERSPECTIVE}

\section{Pablo Bravo-Hurtado*}

\begin{abstract}
RESUMEN: ¿¿Un recurso manifiestamente infundado podría implicar mala fe? Este artículo contesta afirmativamente esa pregunta en base a un estudio comparado de los filtros ante los recursos de casación en Chile, Francia e Italia y de apelación intermedia en el sistema federal de Estados Unidos, Inglaterra y Gales. Se encontraron similitudes importantes en cuestiones como el examen preliminar del fondo, votación por unanimidad, fundamentación abreviada, contradicción de la jurisprudencia, entre otros. La tesis que se propone es que tales similitudes se explicarían por un consenso subyacente acerca de la buena fe en los recursos: un estándar de conocimiento del Derecho exigible a todos los profesionales jurídicos que participan del proceso judicial.
\end{abstract}

Palabras clave: Acceso a la Corte Suprema, filtros ante los recursos, buena fe procesal.

ABSTRACT: Could a manifestly ill-founded appeal imply bad faith? This article answers that question affirmatively based on a comparative study of the filters before the cassation recourse in Chile, France, and Italy and the intermediate appeal in the US federal system and the jurisdiction of England and Wales. Important similarities were found in issues such as the preliminary evaluation of the merits, unanimous vote, abbreviated judicial opinions, contradiction of the case law, among others. The thesis proposed in this article is that these similarities can be explained by an underlying consensus about the good faith in appeals: a standard of knowledge about the Law which applies to all the legal professionals participating in the judicial process.

Key words: Access to Supreme Court, filters before the appeals, procedural good faith.

\section{INTRODUCCIÓN}

Los filtros de acceso a los recursos ante los tribunales superiores suelen ser vistos como un mecanismo para solucionar los problemas de sobrecarga ${ }^{1}$. Estos filtros operarían estableciendo un estándar de importancia que el caso debe superar². En el filtro de "mani-

\footnotetext{
Doctor en derecho (Ph.D) por la Universidad de Maastricht, Países Bajos. Profesor de derecho procesal civil, Pontificia Universidad Católica de Valparaíso, Dirección postal: Av. Brasil 2950, Valparaíso, Chile. Email: pablo.bravo@pucv.cl. Proyecto Fondecyt regular No 1170067: "El principio de la buena fe procesal. Análisis dogmático y crítico de su rol como fuente de cargas, deberes y sanciones en la formación del debate”, investigador principal prof. Dr. Jorge Larroucau Torres.

1 Jolowicz (2000) pp. 328-351. En Chile, Del Río (2015a) pp. 483-513.

2 Domej (2014) pp. 277-290.
} 
fiesta falta de fundamento" de la casación en el fondo chilena ese estándar alude a la calidad mínima de argumentación que deben cumplir los litigantes al interponer un recurso ${ }^{3}$. Pero desde la consagración explícita del principio de buena fe procesal en Chile ${ }^{4}$. nuestra comprensión del filtro de manifiesta falta de fundamento necesita ser repensada. ¿Que un litigante interponga un recurso manifiestamente infundado puede conllevar algún grado de mala fe procesal?

El presente artículo busca contestar esa pregunta a partir de un análisis de Derecho comparado de cinco jurisdicciones: Chile, Francia, Italia, el sistema federal de Estados Unidos y la jurisdicción de Inglaterra que incluye Gales 5 . El artículo se divide en tres partes. Después de una aclaración respecto de cuáles son los tribunales comparables, la primera (II) se aboca a analizar uno a uno cuáles son los filtros y criterios en cada una de estas jurisdicciones. En la segunda (III) estos filtros y criterios son analizados comparativamente. La tesis que se propone es que el mejor modo de explicar las importantes similitudes que se observan entre los filtros de estas jurisdicciones es su relectura desde la buena fe procesal, esto es, como un estándar ético de conocimiento del Derecho exigible a todos los profesionales jurídicos que participan del proceso judicial. La tercera parte y final (IV) da respuesta a tres posibles argumentos contra esta relectura.

\section{PANORAMA COMPARADO}

Según la metodología del funcionalismo del Derecho comparado, en la versión de Zweigert y Kötz, solo pueden compararse instituciones jurídicas que cumplan la misma función ${ }^{6}$. Entre países que pertenecen a la misma familia jurídica -i.e., Chile, España, Francia e Italia dentro de la familia romanista ${ }^{7}$ - encontrar los tribunales comparables resulta más evidente ${ }^{8}$. Además del Tribunal Supremo español, cuya comparación con Chile ya ha sido abordada9, tanto la Cour de cassation francesa como la Corte Suprema di Cassazione italiana aparecen como candidatos naturales para un estudio comparado de la casación en el fondo civil ante la Corte Suprema chilena precisamente por esa tradición jurídica común. Estos tres tribunales comparten la función de proteger la uniformidad de la interpretación mediante la corrección, uno a uno, de los errores de Derecho cometidos por los tribunales inferiores ${ }^{10}$.

3 Núñez Ojeda y Pérez-Ragone (2015) p. 337.

4 Art. 5, Ley No 20.886 de 2016 (tramitación electrónica). LARrouCAu (2017a) pp. 195-234. Sobre la buena fe procesal, Larroucau (2013) pp. 259-305. Para la buena fe procesal en Chile antes de su consagración explícita por esta ley, Gorigoitía (2008) pp. 133-159.

5 Este estudio no incluye la casación civil española porque, si bien es el antecedente directo de la "manifiesta falta de fundamento" chilena, la relación entre Chile y España sobre este punto ya fue suficientemente abordada por GORIGOITÍa (2015) pp. 197-214.

6 Zweigert y KötZ (1998) p. 34.

7 Sobre la familia jurídica romanista, ZwEIGERT y KöTZ (1998) pp. 74-131.

8 Bogdan (2013) p. 71.

9 Por todos, Gorigoitía (2015) pp. 197-214.

10 Para Chile, Muñoz (2010) p. 91. Para Francia, Lamanda (2010) p. 8 (mission disciplinaire). Para Italia, Art. 65 Ordinamento Giudiziario, Coccia (2015) pp. 17-18 (nomofilaquia). 
Ahora bien, encontrar los tribunales comparables entre países que pertenecen a distintas familias jurídicas -i.e., Francia e Italia (familia romanista) vis-á-vis Estados Unidos e Inglaterra (familia anglo-americana) ${ }^{11}$ - es una tarea que dista de ser trivial. Tribunales que tienen nombres similares o que se encuentran en posiciones jerárquicas paralelas pueden cumplir distintas funciones. A diferencia de Francia e Italia, los actores jurídicos locales conciben que la función de la corte suprema de Estados Unidos y el Reino Unido es incompatible con la de corregir errores ${ }^{12}$. Las cortes supremas de Estados Unidos y del Reino Unido son concebidas más bien como cortes de precedentes ${ }^{13}$, combinado con corte constitucional en Estados Unidos ${ }^{14}$. Por esa diferencia de funciones, algunos comparativistas sostienen que, en rigor, las cortes supremas anglo-americanas deberían ser comparadas más bien con los tribunales constitucionales del civil law ${ }^{15}$.

La literatura de Derecho comparado sugiere, en cambio, que las cortes de casación deberían compararse no con las cortes supremas anglo-americanas ${ }^{16}$, sino que con sus cortes intermedias de apelación ${ }^{17}$. En efecto, tanto en Estados Unidos como en Inglaterra los actores jurídicos entienden que la misma función de corregir errores de los tribunales inferiores corresponde más bien a sus cortes intermedias de apelación ${ }^{18}$. En consecuencia, al contrastar las cortes de casación de Chile, Francia e Italia vis-à-vis Estados Unidos e Inglaterra, siguiendo la metodología de Zweigert y Kötz, este artículo se enfocará no en sus cortes supremas, sino que en sus cortes de apelación intermedia. La comparación se hará, en consecuencia, no desde una perspectiva horizontal (contrastando tribunales que estuviesen al mismo tercer nivel jerárquico) sino que diagonal, esto es, tribunales que están en distintos niveles jerárquicos en cada jurisdicción -tercer nivel en Francia e Italia vis-à-vis segundo nivel en Estados Unidos e Inglaterra.

Ahora bien, el objeto de este estudio son los filtros ante los recursos ${ }^{19}$. Para efectos comparados, un "filtro" será definido aquí como una etapa inicial del procedimiento del recurso caracterizado por uno o más requisitos simplificados para rechazar el caso. Así por ejemplo, como regla general el procedimiento ordinario de un recurso puede contemplar

\footnotetext{
11 Sobre la familia jurídica anglo-americana, ZweIgerT y KÖTZ (1998) pp. 180-275.

12 Para la Corte Suprema de Estados Unidos: Wheeler (2004) p. 253. Además, Provine (1980)p. 12; Para la Corte Suprema del Reino Unido: Regina v. Secretary of State For Trade and Industry Ex Parte Eastaway [2000] 1 All ER 27 (HL); en la misma dirección de negar su función de corrección de errores, véase ZuCKERMAN (2013) p. 875; Plant (2004) pp. 1139-1140; Le Sueur y Cornes (2001) p. 40.

13 Para la Corte Suprema de Estados Unidos: Wheeler (2004) p. 253, O’Connor (1984) p. 5; Para la Corte Suprema del Reino Unido: Andrews (2017) p. 38, Drewry y Blom-Cooper (2009) pp. 51-52.

14 Rehnquist (2002) p. 267; Nowak y Rotunda (2004) p. 1, Ferreres Comella (2011) p. 265.

15 Por ejemplo, Rogowski y GaWron (2016) pp. 1-22; Finck (1992) pp. 125-157; Guarnieri y Pederzoli (2002) pp. 134-149.

16 En contra, Cappelletti (1989) p. 142.

17 Jolowicz (2000) p. 299; Geeroms (2004) pp. 278-279; MaK (2013) p. 59.

18 Para Estados Unidos, Wheeler (2004) p. 257; Richman y Reynolds (2013) pp. 2-3. Para Inglaterra, Regina v. Secretary of State For Trade and Industry Ex Parte Eastaway [2000] 1 All ER 27 (HL); Blake y Drewry (2004) pp. 226-227.

19 Sobre filtros de acceso en general, Taruffo (2001); Silvestri (2001); Amrani MekKi (2014); Drago, FaivarQue-Cosson y Goré (2015); Ferraris (2015); Norkus (2015) entre otros.
} 
una fundamentación detallada de la sentencia. En la etapa de filtro, en cambio, al tribunal se le permite rechazar el recurso con una fundamentación breve o sin fundamentación ${ }^{20}$. Otra simplificación es la composición del panel de jueces. En el procedimiento ordinario del recurso el caso suele ser resuelto por el panel completo de jueces -i.e., cinco, siete o nueve, dependiendo del tribunal- mientras que en la etapa de filtro el caso puede ser rechazado por un panel reducido de, por ejemplo, solo tres. Una última simplificación son los alegatos orales. Si el procedimiento ordinario contempla alegatos orales para las partes, en la etapa de filtro tales alegatos orales podrían omitirse ${ }^{21}$.

\section{CHILE}

En Chile el filtro de "manifiesta falta de fundamento" no se encuentra aún en los tribunales de primera instancia en materias civiles $^{22}$, sino que en ciertos recursos ante los tribunales superiores ${ }^{23}$. Influenciado por la casación española de la anterior Ley de Enjuiciamiento Civil ("carezca manifiestamente de fundamento")24, la reforma chilena de 1995 consagró en la casación en el fondo ante la Corte Suprema tal filtro en virtud del artículo 782 del Código de Procedimiento Civil, del siguiente modo:

"Art. 782. Elevado un proceso en casación de fondo, el tribunal examinará en cuenta [los requisitos de admisibilidad]. - La misma sala, aun cuando se reúnan los requisitos [...] podrá rechazarlo de inmediato si, en opinión unánime de sus integrantes, adolece de manifiesta falta de fundamento. - Esta resolución deberá ser, a lo menos, someramente fundada $[\ldots]^{\prime 25}$.

Las condiciones simplificadas de este filtro chileno son básicamente dos. Por una parte, se decide sin alegatos orales de los abogados ("en cuenta") y, por la otra, para el rechazo preliminar basta una fundamentación abreviada ("someramente"). Respecto del criterio mismo, sin embargo, el proyecto de ley original de esta reforma además buscaba introducir un filtro de interés jurisprudencial definido como "relevancia para la adecuada interpretación o aplicación del Derecho" ${ }^{26}$. Sin embargo, tal filtro fue rechazado por el Tribunal Constitucional ${ }^{27}$, quedando así solo el filtro de manifiesta falta de fundamento.

\footnotetext{
20 Ferrand (2015) pp. 186-188; Norkus (2015) p. 6; en general, Galic (2014) pp. 159-174.

21 Del Rio (2015a) p. 487.

22 Pero sí en materias de familia como "manifiestamente improcedente", LARrouCAU (2017b) pp. 441-456. Sobre la propuesta de introducir este filtro en la primera instancia civil, véase HunTER (2009) pp. 117-163.

23 Hoy en día este filtro se encuentra no solo ante la Corte Suprema en materia civil. En materia de familia tal filtro también se encuentra ante la Corte Suprema en virtud de la casación en el fondo civil aplicada supletoriamente (Ley No 19.968 de 2004: Art. 67). Expresiones semánticamente equivalentes -i.e., "carencia” de fundamentos- se encuentran como filtro ante las Cortes de Apelaciones en los actuales recursos de nulidad penal (Código Procesal Penal: Art. 383 inc. $2^{\circ}$ ) y laboral (Código del Trabajo: Art. 480 inc. 5º). La misma expresión se contempla además en la revisión de sentencias firmes penales (Código Procesal Penal: Art. 475 inc. $3^{\circ}$ ).

24 Ley de Enjuiciamiento Civil (1881) Art. 1710 (3). Gorigoitía (2015) p. 206.

25 Figueroa y Morgado (2014) pp. 161-162.

26 Mosquera y Maturana (2010) p. 315; Núñez Ojeda y Pérez-Ragone (2015) pp. 336-339.

27 Tribunal Constitucional (1995) Rol No 205-95, cons. $8^{\circ}$.
} 
Ahora bien, ¿qué se ha entendido por "manifiesta falta de fundamento" en Chile? Un primer consenso en la doctrina chilena es que no se trata de un examen de requisitos simplemente formales, sino que sobre el fondo ${ }^{28}$. Respecto del estándar para ese examen del fondo, sin embargo, autores como Núñez Ojeda y Pérez-Ragone afirman que es una "incógnita”, se trata de un término legalmente indefinido que la Corte Suprema decidirá caso a caso ${ }^{29}$. En el mismo sentido, Gorigoitía critica que el principal defecto de este filtro es su "abierta imprecisión"30. Otros autores que intentan definir esta noción más bien agregan sinónimos. Por ejemplo, según Atria el error debe ser "suficientemente evidente" 31 . Para Tavolari debe tratarse de un recurso "brutalmente desprovisto de razón [y] tan pobre [en] su motivación" que los jueces lo rechazarían en base a su sola lectura ${ }^{32}$. Que sea manifiesto significa, según Piedrabuena, que el error es "ostensible y evidente y no requiere un estudio más a fondo" ${ }^{33}$. Según Collados significa que la fundamentación exhibe un error tan "brutal, manifiesto, evidente, superficial [o] indiscutible" que sería rechazado solo en base a un ligero examen del recurso ${ }^{34}$. Romero et al., en cambio, han tenido una aproximación distinta. En su investigación han buscado hacer un catastro de los distintos argumentos por los que la Corte Suprema rechaza en admisibilidad los recursos de casación, incluyendo la manifiesta falta de fundamento ${ }^{35}$. Entre los argumentos catastrados destaca que la Corte Suprema ha entendido como manifiestamente infundado un recurso que va en contra de la jurisprudencia asentada por la misma Corte $^{36}$.

En sus fallos, la Corte Suprema chilena ha seguido, en general, la definición literal de "manifiesto" otorgada por la Real Academia Española, a saber, "descubierto, patente, claro" ${ }^{37}$. En particular, su jurisprudencia sobre manifiesta falta de fundamento en la casación en el fondo, si bien sumamente casuística ${ }^{38}$, suele repetir ciertas cláusulas que dan a entender qué entiende por tal. Después de una breve refutación del argumento del recurrente en dos o tres frases - "someramente fundada" dice el Art. 782- la Corte Suprema suele justificar su rechazo preliminar en virtud de la "clara inexistencia del error de Derecho" 39 , o que "se observa que los sentenciadores [...] efectuaron una correcta aplicación de la normativa atinente al caso" ${ }^{30}$. Por último, en opinión de la Corte Suprema, al

\footnotetext{
28 Libedinsky (1995) pp. 7-8; Mosquera y Maturana (2010) p. 316; Palomo (2016) p. 346; Del Río (2015a) p. 487.

29 Núnez Ojeda y Pérez-Ragone (2015) p. 336.

30 Gorigoitía (2015) p. 208.

31 Atria (2005) p. 289.

32 Tavolari (1996) p. 71.

33 Piedrabuena (1996) p. 168

34 Collados (2005) p. 39.

35 Romero et al. (2008) pp. 231-232; Romero (2013) pp. 52-63.

36 Romero et al. (2008) p. 232; Romero (2013) pp. 59-60; Sobre cómo debe ser entendido, Del Río (2015b) pp. 483-513.

37 Por ejemplo, LABBÉ CON REYes (2011) cons. 6o; MATAMALA WALTER, OlGA GRACIELA CON CORPBANCA (2007) cons. 9.

38 Para una análisis estadístico del control de admisibilidad de la casación civil chilena entre el 2000-2004, véase ISRAEL (2006), pp. 191-203.

39 Por ejemplo, URTUBIA CON INMOBILIARIA QUILLAY (2014) cons. 5.

40 Entre muchos, véase, DEL INCA CON UGALDE (2010) cons. 13; MILLAR CON INMOBILIARIA LIRCAY (2014) cons. 11\%; SCHWARSENBERG CON SCHWARSENBERG (2010) cons. 8º; IBARRA CON ARAVENA (2010) cons. $14^{\circ}$.
} 
comentar el proyecto de nuevo código procesal civil para Chile, estimó que en virtud del filtro de manifiesta falta de fundamento la Corte "cuenta ya con [...] discrecionalidad para seleccionar casos" ${ }^{41}$.

\section{FRANCIA}

La Cour de cassation originalmente tenía una cámara dedicada a la función de filtro, a saber, la chambre des requêtes. Pero ella dejó de existir en cuanto tal en 1947, transformándose en una cámara ordinaria en materias civiles ${ }^{42}$. Sin embargo, una especie de filtro empezó a resurgir en Francia tres décadas después. En efecto, la reforma de 1979 permitió que las cámaras ordinarias de la Cour de cassation enviaran el caso a una "formación restringida" de solo tres jueces (formation restreinte) ${ }^{43}$, siendo que la composición normal suele ser de cinco o más ${ }^{44}$. La tarea de esta formación restringida es resolver casos, ya sea rechazando el recurso o casando la sentencia inferior, cuando la solución aparece clara a partir del expediente (la solution du pourvoi simpose) ${ }^{45}$. En otras palabras, la formation restreinte está a cargo de decidir rápidamente los casos fáciles. Inicialmente se pensó que este envío de casos a la formation restreinte sería una práctica excepcional. Sin embargo, en 1997 esta práctica se convirtió en la regla general ${ }^{46}$. Desde entonces, todos los recursos de casación francés primero pasan por la formation restreinte antes de que sean transferidos a alguna de las cámaras ordinarias de la Cour de cassation ${ }^{47}$. En este sentido, la fomation restreinte se convirtió en un filtro preliminar. En esta etapa inicial está permitido rechazar recursos con un panel reducido de jueces, sin una sentencia con fundamentación detallada ${ }^{48}$, y la decisión se toma sobre la base de los escritos presentados por las partes, omitiendo alegatos orales ${ }^{49}$. El criterio de filtro de la formation restreinte es el nuevo procedimiento de inadmisibilidad (procédure de non-admission $)^{50}$. El criterio del filtro está consagrado en el artículo 1014 del Code de procédure civile. Dado que el criterio mismo ha evolucionado de un modo particular, aquí se mencionarán sus últimas dos versiones:

41 Corte Suprema Chilena (2013) p. 11.

42 Ferrand (2017) pp. 190-191.

43 Sobre los orígenes de esta formación restringida, véase Perdriau (1994); la Corte de Casación francesa solía tener una cámara separada para el filtro preliminar, la así llamada chambres des requêtes, hasta 1947. En ese año, esta cámara de filtro francesa fue reformada en lo que ahora constituye la cámara para asuntos comerciales. FERRAND (2017) pp. 190-191.

44 Weber (2010) p. 69; WijfFels (2013) p. 81.

45 Boré y Boré (2015) p. 72.

46 Boré y Boré (2015) p. 72.

47 Code de l'organisation judiciaire - Loi du 23 avril 1997, Art. L431-1, primer inciso.

48 Code de procédure civile, Art. 1014; FerRAnd (2017) pp. 200-201.

49 Code de procédure civile, Art. 1014 (“... Après le dépôt des mémoires...”), esta expresión del lenguaje jurídico francés puede se traducido como "después de las presentaciones escritas [de las partes]"; Boré y Boré (2015) p. 657.

50 En detalle sobre el procedimiento de inadmisibilidad francés, Vigneau (2010) pp. 102-111. 
Versión 2009 - "Art. 1014. Después que las partes depositen sus escritos del recurso (mémoires), esta formación [restringida] declara no admitidos los recursos inadmisibles (irrecevables) o no fundados en un medio serio de casación" ${ }^{\prime 1}$.

Versión 2014 - "Art. 1014. Después que las partes depositen sus escritos del recurso (mémoires), esta formación [restringida] decide que no es necesario una decisión especialmente fundamentada cuando el recurso es inadmisible (irrecevable) o cuando manifiestamente no es de la naturaleza para concluir en casación"52.

Como podemos ver, anteriormente la formation restreinte evaluaba si acaso el recurso "no se fundaba en un medio serio de casación" (non fondés sur un moyen sérieux de cassation $)^{53}$. Sin embargo, en el 2014 el criterio de filtrado cambió a un recurso que "manifiestamente no es de la naturaleza para concluir en casación" (lorsqu'il n'est manifestement pas de nature à entraîner la cassation $)^{54}$.

Ahora bien, ¿qué significan estos criterios de filtro en Francia? En primer lugar, no es un filtro de requisitos puramente formales (irrecevables) ${ }^{55}$. El procédure de non-admission también evalúa la fuerza y consistencia de los argumentos de las partes en sus presentaciones escritas ${ }^{56}$. Respecto de este examen del fondo, sin embargo, Boré y Boré reconocen que es difícil marcar una diferencia entre una casación "seria" y una casación adecuadamente "fundada" 57 . Ausencia de "seriedad", podríamos concluir, es un sinónimo cercano a ausencia de "fundamentación" del recurso. Para Buffet son aquellos que "no producen ninguna duda acerca de su ineficacia" para lograr la casación y que, en base a un examen "superficial y rápido" del recurso, resulta evidente que no poseen ninguna "chance razonable de éxito" (chance raisonnable de succès) ${ }^{58}$. Por último, los autores franceses suelen negar que este filtro de la formation restreinte pueda consistir en una evolución hacía una selección "discrecional" de los recursos 59 .

\footnotetext{
51 Traducción propia ("Après le dépôt des mémoires, cette formation déclare non admis les pourvois irrecevables ou non fondés sur un moyen sérieux de cassation”), Décret No 2008-522 du 2 juin 2008 - art. 9.

52 Traducción propia ("Après le dépôt des mémoires, cette formation décide qu'il n’y a pas lieu de statuer par une décision spécialement motivée lorsque le pourvoi est irrecevable ou lorsqu'il n'est manifestement pas de nature à entrâेner la cassation"), Décret No 2014-1338 du 6 novembre 2014 - art. 19.

53 Sobre el procedimiento de inadmisibilidad durante este periodo, Amrani-MeKKI (2005) pp. 19-31. Originalmente en el Code de l'organisation judiciaire, Art. 131-6, desde la reforma de la Loi No 2001-539 du 25 juin 2001. Después de ella, esta disposición fue trasladada al Art. 1014 del Code de procédure civile en 2008 por el Décret No 2008-522 du 2 juin 2008.

54 Esto después de la reforma Décret No 2014-1338 du 6 novembre 2014; BORÉ y BORÉ 2015, pp. 656-658.

55 Sobre los requisitos puramente formales ('irrecevables' en terminología jurídica francesa), BuffET (2005) pp. 106-107; VigneAu (2010) pp. 106-107; BorÉ y Boré (2015) pp. 91-96.

56 Armani-MekKi (2005) pp. 24-25.

57 Boré y Boré (2015) p. 656.

58 Buffet (2005) p. 108.

59 Por ejemplo, según FERRAND (2017) p. 196: "la Cour de cassation 'no posee discreción para seleccionar cuáles recursos tomará en consideración' [has no discretion to select which appeals it will consider]".
} 
3. ITALiA

En Italia, a pesar del derecho constitucional a la casación ${ }^{60}$, la reforma del 2009 introdujo un filtro preliminar para la Corti di Cassazione $e^{61}$. Para tal propósito, se creó la sexta cámara civil (sesta sezione civile) también conocida como la cámara de filtro (sezione filtro) ${ }^{62}$. Esta cámara de filtro está dividida en cinco $\operatorname{salas}^{63}$. Cada sala de filtro está especializada en concordancia con las otras cinco cámaras ordinarias para materias civiles lato sensu ${ }^{64}$. Cada sala de filtro está compuesta de un presidente no-titular y cuatro jueces ordinarios de casación (consiglieri) que provienen de las correspondientes cámaras ordinarias ${ }^{65}$. En la práctica, las salas italianas de filtro trabajan en paneles de cinco jueces, del mismo modo que lo hacen las cámaras civiles ordinarias ${ }^{66}$. Ahora bien, el criterio de filtro quedó consagrado en el nuevo artículo 360 bis del Codice di Procedura Civile, del siguiente modo:

"Art. 360 bis. El recurso es inadmisible:

(1) Cuando la resolución impugnada ha decidido una cuestión de Derecho de modo conforme a la jurisprudencia de la Corte [Suprema de Casación] y el examen de los fundamentos no ofrece elementos para confirmar o cambiar la dirección de la misma.

(2) Cuando está manifiestamente infundada la denuncia relativa a la violación de los principios reguladores del debido proceso" ${ }^{37}$.

Ahora bien, ¿qué significan estos dos nuevos criterios de filtro en Italia? El primer consenso que pareciera existir en la doctrina italiana es que, contrario a lo que señala el encabezado del artículo, este no es un genuino filtro de "admisibilidad" entendido como evaluación de requisitos formales ${ }^{68}$. Se trataría, en realidad, de una evaluación sobre el fondo en base al estándar de "manifiestamente infundado". Ese criterio de examen del fondo es explícito en la segunda causal (art. 360 bis 2) respecto de las violaciones al debido proceso (manifestamente infondata) ${ }^{69}$. Sin embargo la primera causal (art. 360bis 1) no lo señala explícitamente $^{70}$. Mas la doctrina italiana también entiende que la primera causal de no

60 Costituzione della Republica Italiana, Art. 111.

61 Sobre los detalles de esta reforma, Ferraris (2015) pp. 167-174.

62 Ferraris (2015) pp. 208-212.

63 Corte Suprema di Cassazione 2013 (\$ 39.1) p. 27.

${ }^{64}$ Ferraris (2015) pp. 211-212; para críticas al funcionamiento de la sexta cámara de filtro, Macioce (2015) pp. 392-395.

65 Corte Suprema di Cassazione (2013) \$ 39.1, p. 27.

66 Ordinamiento Giudiciario, Art. 67; Ferraris (2015) p. 210.

67 Traducción propia ("Il ricorso è inammissibile: 1) quando il provvedimento impugnato ha deciso le questioni di diritto in modo conforme alla giurisprudenza della Corte e l'esame dei motivi non offre elementi per confermare o mutare l'orientamento della stessa; 2) quando è manifestamente infondata la censura relativa alla violazione dei principi regolatori del giusto processo") Codice di Procedura Civile, Art. 360 bis; FERRARIS (2015) pp. 184-205.

68 Por todos, Comoglio et al. (2011) p. 720.

69 Amoroso (2012) pp. 432-435; Ferraris (2015) pp. 196-205; para comentarios críticos, Macioce (2015) pp. 391-392.

70 Ferraris (2015) pp. 188 y ss. 
contradicción de la jurisprudencia en realidad cuenta como un criterio de "manifiestamente infundado" también ${ }^{71}$. Desde este punto de vista, ambas causales refieren a un filtro de manifiesta falta de fundamento en que la segunda refiere a cuestiones de derecho procesal y la primera a cuestiones de derecho substantivo-jurisprudencial. Por último, ciertos autores italianos critican que la expresión literal manifestamente infondata podría entregar cierto grado de discrecionalidad a la Corte di Cassazione ${ }^{72}$, pero no al nivel de la total discrecionalidad del writ of certiorari de la Corte Suprema de Estados Unidos ${ }^{73}$.

\section{INGLATERRA Y GALES}

Actualmente en Inglaterra y Gales el filtro ante la apelación intermedia es el "permiso" (permission to appeal, anteriormente llamado leave to appeal) que la reforma Woolf de 1999 extendió de las sentencias interlocutorias a las sentencias definitivas ${ }^{74}$. El permiso para apelar se solicita tanto ante el tribunal inferior (a quo) como ante el superior ( $a d$ quem $)^{75}$. La primera simplificación de este filtro es que el procedimiento es de naturaleza escrita ante el tribunal ad quem ${ }^{76}$. La Court of Appeal, y ahora también la High Court, generalmente toma la decisión de otorgar o no el permiso sin alegatos orales, sino solo en base a los escritos de las partes ${ }^{77}$. Si el permiso para apelar es denegado ante el tribunal ad quem, sin embargo, el litigante tiene la posibilidad de solicitar una audiencia de alegato oral para que se reconsidere el permiso (reposición) ${ }^{78}$. Pero si el tribunal ad quem considera que el recurso "carece totalmente de mérito", el tribunal rechazará de antemano esa posibilidad de reconsideración mediante alegato oral $^{79}$. La segunda simplificación es que, si bien el rechazo del permiso debe ser fundamentado ${ }^{80}$, en la práctica la fundamentación que otorga el tribunal ad quem es extremadamente concisa, usualmente un párrafo de un cuestionario breve $^{81}$. El criterio para filtrar casos en el permiso para apelar inglés está consagrado en la sección 52.3 (6) de las Civil Procedure Rules, del siguiente modo:

"Section 52.3 (6) El permiso para apelar puede ser otorgado solo cuando (a) la corte considera que la apelación podría tener una expectativa real de éxito; o (b) existe alguna otra razón convincente por la que la apelación deba ser escuchada” ${ }^{\$ 2}$.

\footnotetext{
71 Amoroso (2012) pp. 437-439; Ferraris (2015) pp. 178.181.

72 Comoglio et al. (2011) p. 721.

73 TARuffo (2011) p. 31.

74 ZuCKerman (2013) pp. 1112-1113; Andrews (2014) pp. 76-77.

75 En detalle, Drewry, Blom-Cooper y Blake (2007) pp. 67 y ss.

76 El permiso para apelar ante el tribunal a quo, sin embargo, puede ser planteado oralmente, ZUCKERMAN (2013) p. 1147.

77 Practice Direction 52C - Appeals to the Court of Appeals. Rule 15 (1); ZuCKerman (2013) p. 1149.

78 Civil Procedure Rules, Rule 52.3 (4); Drewry, Blom-Cooper y Blake (2007) p. 70.

79 Civil Procedure Rules, Rule 52.3 (4A) (a).

80 Practice Direction 52C - Appeals to the Court of Appeals. Rule 15 (1).

${ }^{81}$ Para un ejemplo de este cuestionario para el permiso para apelar en los tribunales inferiores, véase: wbus. westlaw.co.uk/forms/pdf/cpf09262.pdf.

82 Traducción propia ("(6) Permission to appeal may be given only where - (a) the court considers that the appeal would have a real prospect of success; or (b) there is some other compelling reason why the appeal should be heard")
} 
Como podemos ver, los criterios para otorgar el permiso para apelar en Inglaterra y Gales son básicamente dos. Por una parte, el requisito de "expectativa real de éxito" (real prospect of success) y, por la otra, el requisito de "alguna otra razón convincente" (some other compelling reason $)^{83}$. De entre estos dos, el segundo criterio -i.e., alguna otra razón convincente- es raramente utilizado ${ }^{84}$. En consecuencia, aquí la atención estará en el primer criterio (real prospect of success), como un cuadro más representativo de las prácticas del permiso para apelar en Inglaterra.

Ahora bien, ¿qué se ha entendido por "expectativa real de éxito" en Inglaterra? En el fallo Swain v. Hillman, particularmente en el voto de Lord Woolf, se explica el significado de esta frase:

"Las palabras 'no existen expectativas reales de éxito o de que sea exitoso' no necesitan de ninguna aclaración, ellas hablan por sí mismas. La palabra 'real' se distingue de las expectativas fantasiosas/imaginarias [fanciful] de éxito... [Estas palabras] guían a la Corte a la necesidad de ver si acaso existe una expectativa 'realista' por oposición a una expectativa 'fantasiosa' de éxito" 85 .

Como podemos ver, el criterio inglés de "expectativa real de éxito" también es un examen preliminar del fondo. Esto porque la causal para interponer la apelación inglesa es que la decisión del tribunal inferior está "equivocada" (wrong) ${ }^{86}$. Por lo tanto, un recurso de apelación que carece de expectativas reales de éxito será aquel recurso en que resulta evidente que no existe tal equivocación del tribunal inferior. Ahora bien, respecto del criterio de filtro (real prospect of success), en la opinión dominante de Lord Woolf una definición resultaría innecesaria porque tales palabras "hablan por sí mismas", limitándose a definir el antónimo de "real" como "fantasioso".

\section{Estados Unidos}

En la cultura jurídica de los Estados Unidos está arraigado un derecho a (una) apelación $^{87}$. Aún así, las cortes federales de apelación desarrollaron a lo largo del tiempo un tipo de filtro. Para adaptarse a una explosión en la carga de casos, estos tribunales también implementaron, entre otras medidas, una etapa inicial con condiciones simplificadas para rechazar casos ${ }^{88}$. De acuerdo a las Federal Rules, un primer panel de tres jueces puede decidir,

Civil Procedure Rules, section 52.3 (6)(a)(b)

83 ZuCKerman (2013) pp. 1156-1157.

84 Drewry, Blom-Cooper y Blake (2007) p. 71.

85 Traducción propia ("The words "no real prospect of being successful or succeeding" do not need any amplification, they speak for themselves. The word "real" distinguishes fanciful prospects of success or ... they direct the court to the need to see whether there is a "realistic" as opposed to a "fanciful" prospect of success"). Swain v. Hillman [1999] EWCA, para. 7; también, DreWry, Blom-COOPER y BlaKe (2007) p. 70.

86 Civil Procedure Rules, Rule 52.11 (3) (a) (b).

87 Marcus (2014) p. 112.

88 En detalle, Bowie, Songer y Szmer (2014) pp. 30 y ss. 
unánimemente, no conceder alegatos orales para el recurso ${ }^{89}$. En la práctica, sin embargo, este filtro no es realizado por los jueces de apelación mismos, sino que lo delegan a los law clerks $\mathrm{u}$ otros funcionarios del tribunal ${ }^{90}$. Más aún, el procedimiento mismo de este filtro no es de naturaleza oral, sino que se basa en las presentaciones escritas de las partes y en el expediente judicial ${ }^{91}$. Este filtro también contempla la condición simplificada de un estándar más bajo para la fundamentación del rechazo. Este rechazo simplificado puede ser el resultado de una resolución que no se hace pública, que suelen contener una fundamentación (demasiado) concisa con un razonamiento de baja calidad -i.e., sentencias "basura", como se les llama peyorativamente ${ }^{92}$. Además, el rechazo simplificado también puede ser el resultado de las así llamadas orders, similares a nuestros "autos" o "decretos", resoluciones en que está permitido que se dicten sin ninguna fundamentación, bastando tan solo la palabra "confirmado" $"$. Por lo tanto, lo que constituye un filtro preliminar en las cortes federales de apelación en los Estados Unidos será esta etapa inicial en que se decide si conceder o no alegatos orales ${ }^{94}$. El criterio de este filtro está consagrado en la regla 34 (2) de las Federal Rules of Appellate Procedure, del siguiente modo:

"Rule 34 (2) Estándar. Los alegatos orales deben ser permitidos en todos los casos salvo que un panel de tres jueces que examinaron los escritos de las partes y el expediente están de acuerdo unánimemente que los alegatos orales son innecesarios por alguna de las siguientes razones:

(a) La apelación es frívola;

(b) La parte dispositiva [del fallo impugnado] ha sido autoritativamente decidida; o

(c) Los hechos y argumentos jurídicos están adecuadamente presentados en los escritos y en el expediente, y los alegatos orales no ayudarán significativamente al proceso de decisión" 95 .

Como podemos ver, el criterio general en este filtro inicial es si acaso son necesarios o no alegatos orales. Sin embargo, los alegatos orales resultan innecesarios no solo si las presentaciones escritas de las partes y el expediente judicial son suficientes para resolver el caso. En las cortes federales de apelación de los Estados Unidos, el criterio de filtrado también aparece como un examen preliminar del fondo. A la corte le está permitido excluir

89 Federal Rules of Appellate Procedure, Title VII, Rule 34 (2)(a).

90 Richman y Reynolds (1996) pp. 286-292. Hooper, Miletich y Levy (2011) pp. 16-17.

91 Federal Rules of Appellate Procedure, Title VII, Rule 34 (2)(a); Castanias y Klonoff (2008) p. 270.

92 Richman y Reynolds (1996) p. 284.

93 Federal Rules of Appellate Procedure, Title VII, Rule 36. Richman y Reynolds (1996) p. 285.

94 Sobre los criterios procesales en esta etapa inicial, CROss (2007) pp. 178 y ss.

95 Traducción propia ("(2) Standards. Oral argument must be allowed in every case unless a panel of three judges who have examined the briefs and record unanimously agrees that oral argument is unnecessary for any of the following reasons: (A) the appeal is frivolous; $(B)$ the dispositive issue or issues have been authoritatively decided; or $(C)$ the facts and legal arguments are adequately presented in the briefs and record, and the decisional process would not be significantly aided by oral argument."). Federal Rules of Appellate Procedure. Rule 34 (2). 


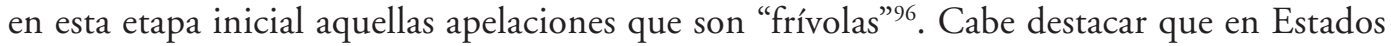
Unidos la frivolidad de la apelación no solo restringe el acceso al recurso, sino que además puede conllevar sanciones ${ }^{97}$.

Ahora bien, ¿qué se entiende por apelación "frívola" en Estados Unidos? En general, los estudios sobre este tema se basan en las conclusiones de Martineau ${ }^{98}$. Según este autor, la jurisprudencia define una apelación como frívola si es "totalmente sin mérito" o "no tiene chances de éxito" " Una apelación será así frívola si la resolución impugnada no es la sentencia definitiva, la acción está prescrita o la corte no tiene competencia ${ }^{100}$. Pero respecto del fondo o mérito, continúa Martineau, una apelación se considera frívola si "no tiene fundamento jurídico" (has no legal basis). Así, por ejemplo, si se argumenta en contra de un precedente claramente establecido hace mucho tiempo sin otorgar razones para cambiar la jurisprudencia, si la apelación argumenta cuestiones que no se basan en los hechos del caso o si del escrito de apelación no se puede extraer ningún argumento inteligible ${ }^{101}$.

\section{ANÁLISIS: BUENA FE EN LOS RECURSOS}

Los criterios de filtro en estos tribunales no están formulados en los exactos mismos términos literales. De entre las distintas formulaciones las que más se asemejan literalmente al filtro chileno son la casación de Italia -i.e., "manifestamente infondata" pero consagrado explícitamente solo para vicios procesales- y la de Francia, que comparte la expresión "manifestement". Los criterios de filtro para la apelación intermedia en Estados Unidos e Inglaterra, en cambio, aparecen literalmente más distanciados de la formulación chilena: recursos "frívolos" (EE.UU.) o que no tienen una "expectativa real de éxito" (Inglaterra).

Más allá de estas diferencias literales, como veremos, existen una serie de similitudes importantes en los filtros ante los tribunales comparables en estas cinco jurisdicciones. Ahora bien, que existan tales similitudes -incluso entre jurisdicciones que pertenecen a distintas familias jurídicas y entre tribunales que se encuentran a distintas alturas de la jerarquía judicial- nos llama a buscar alguna explicación común que aplique a estas cinco jurisdicciones. En este apartado propondré que esa explicación común es la relectura de la "manifiesta falta de fundamento" como un filtro de buena fe procesal en los recursos, del siguiente modo.

La buena fe procesal aplica no solo a la formación del debate en las primeras instancias. En los recursos también existe una formación del debate, pero, según Oldfather, "derivada" o de segundo orden: un debate acerca del debate que se tuvo en la instancia anterior $^{102}$. La manifiesta falta de fundamento aludiría así a un estándar ético en la formación de ese debate de segundo orden acerca del nivel mínimo de conocimiento o dominio del Derecho. Y -aquí está lo importante- ese estándar mínimo es, por así decirlo, erga omnes dentro

\footnotetext{
96 En general, Castanias y Klonoff (2008) pp. 271-272.

97 Kravitz (2002) p. 337.

98 Martineau (1984) pp. 845-886; Kravitz (2002) pp. 335-348; Rasch (2009) pp. 249-285.

99 Martineau (1984) p. 850.

100 Martineau (1984) p. 850.

101 Martineau (1984) p. 851.

102 Oldfather (2010) p. 81.
} 
de la comunidad jurídica. Esto es, exigible a todos los profesionales del Derecho que participan del proceso judicial, tanto jueces como abogados. En otras palabras, un recurso que no pasa este estándar mínimo implicaría que su falta de fundamento jurídico es tan "manifiesta" que debería resultar evidente no solo para los jueces del tribunal, sino que incluso para el propio abogado que lo interpuso. De este modo, los recursos que no pasan este filtro implicarían, directa o indirectamente, una mala fe procesal en cuanto infringiría ese estándar ético de conocimiento mínimo del Derecho. Así visto, la "manifiesta falta de fundamento" constituye un mecanismo preventivo de la buena fe procesal. Este filtro impide que un recurrente dilate el procedimiento mediante la interposición de recursos basándose en argumentos que él mismo sabe, o debería saber, resultan infundados. Como veremos, la subyacente infracción de ese estándar ético de conocimiento mínimo del Derecho pareciera ser el mejor modo de explicar las similitudes que se encuentran entre estas cinco jurisdicciones.

\section{EXAMEN DEL FONDO Y DERECHO A RECURSO}

La primera similitud es que el criterio de filtro no es visto como la evaluación de requisitos puramente formales. No se trataría tan solo de evaluar, por ejemplo, si el escrito del recurso fue interpuesto dentro de plazo o ante el tribunal competente. Detrás de estas distintas formulaciones subyace, con ciertas variaciones de énfasis, una misma idea abstracta acerca de un examen preliminar del fondo, acerca del mérito sustantivo o peso de los argumentos jurídicos invocados por el recurrente. Sobre este punto el caso más interesante fue Italia, donde la negación del carácter puramente formal del filtro pareciera ir incluso contra texto expreso de su ley (inammissibile).

Ahora bien, ¿por qué sería necesario una evaluación anticipada que incluya no solo los requisitos de forma? ¿Por qué la evaluación del mérito de los argumentos no se deja para el procedimiento ordinario posterior del recurso? Una explicación pragmática -i.e., economía procesal- sería que esto ahorra costos del tribunal. No sería necesario invertir mayor tiempo y recursos en un caso cuya decisión (desfavorable) aparece clara desde un comienzo.

Desde la buena fe procesal, sin embargo, la revisión detallada por el tribunal de un recurso manifiestamente infundado no solo resulta innecesaria, sino que tampoco es merecida. Recordemos que tanto en Italia, Francia y Estados Unidos existe un derecho fuerte al recurso (de casación o primera apelación, respectivamente) ya sea constitucional o culturalmente. En virtud de ese derecho al recurso, diríamos, todo litigante tiene derecho a que el tribunal superior evalúe detalladamente el fondo de su impugnación. ¿Cómo se explica entonces que el filtro de manifiesta falta de fundamento exista en estas jurisdicciones a pesar de existir, al mismo tiempo, un derecho fuerte al recurso? Introducir filtros a los recursos aparecería, en principio, como contradictorio con el derecho a recurso mismo. Pero visto desde la buena fe procesal esta contradicción se resuelve: la protección del derecho a recurso no incluye el abuso de ese derecho. Es posible tener derecho a recurso y manifiesta falta de fundamento porque, visto como un filtro de buena fe procesal, este excluye los abusos de aquel.

\section{INNECESARIA DEFINICIÓN}

Los criterios de filtro observados fijan una especie de vara o estándar de calidad mínima que esos argumentos sustantivos deben superar. Para saber qué tan alto o bajo es 
ese estándar fue necesario buscar las definiciones que se dan a los términos literales en que está formulado el criterio de filtro en cada jurisdicción. Sin embargo, aquí el estudio comparado se enfrentó a un problema de redundancias. Lo que se encuentra son sinónimos tales como "evidente", "sin duda", "claro", "abiertamente" o antónimos como "fantasioso", "frívolo", "totalmente sin mérito" o incluso "brutal". El caso más interesante fue el permiso para apelar inglés. Ahí no solo no existe una definición de real prospect of success sino que UNA definición tal les resultaría innecesaria porque -en la opinión de Lord Woolf- los términos "hablan por sí mismos"103.

En cualquier jurisdicción, hacer una definición de "manifiesta falta de fundamento" (o sus equivalentes) sería interminable. Todas las posibles variantes en que el argumento de un litigante podría contradecir las reglas de Derecho sería tan o más numerosa como la cantidad total de reglas que el Derecho de ese país tiene. Pero visto desde la buena fe procesal, en concordancia con la aproximación inglesa, una enumeración tal resulta además innecesaria. Pertenecer y participar en una comunidad profesional presupone un piso compartido consistente en un lenguaje y conocimiento común. En la comunidad profesional del Derecho ese piso compartido son los conceptos jurídicos, las reglas, principios y forma de articular unos y otros en argumentos al operar dentro de las instituciones judiciales. Por lo tanto, entre los abogados y jueces de una jurisdicción (presuponiendo que es requisito una educación jurídica mínima) no se necesita una definición de "manifiesta falta de fundamento" -i.e., de aquellos conceptos, reglas y formas de argumentación básicas que se deben respetar dentro del Derecho- precisamente porque ellos son profesionales jurídicos, es de suponer que ya las saben.

En esto Chile es un caso interesante de cómo el conocimiento del Derecho constituye un estándar de buena fe. Según el código civil chileno, “...nadie puede alegar la ignorancia de la ley...” (art. 8) y “...un error en materia de Derecho constituye presunción de mala fe...” (art. 706). Dada la aplicación general del código civil, obviamente, estas disposiciones también aplican a los litigantes que interponen recursos. Por lo tanto, en Chile constituría mala fe si un litigante intentara justificar la interposición de un recurso manifiestamente infundado - esto es, en que (evidentemente) no existe un error de Derecho ${ }^{104}$ basado en que desconocía la ley.

\section{Sin eXPectativas De ÉXito}

A la hora de explicar con otras palabras en qué consiste el criterio de este filtro, existe una frase que se repite casi literalmente en las distintas jurisdicciones. En diferentes idiomas, los autores afirman que no debería pasar este tipo de filtro un caso que no tiene expectativas, posibilidades o chances de éxito o de prosperar. Ya vimos que en Inglaterra tal criterio está consagrado explícitamente en el permiso para apelar, a saber, no real prospect of success $^{105}$. En Estados Unidos, Martineau explica la jurisprudencia sobre apelaciones frívolas

\footnotetext{
103 SWAin V. HiLlman [1999] EWCA, párr. 7.

104 Figueroa y Morgado (2014) pp. 161-161.

105 Civil Procedure Rules, section 52.3 (6)(a).
} 
diciendo que, entre otras cosas, son aquellas que tienen no chance of success ${ }^{106}$. Y en Francia, Buffet explica que una casación sin fundamentos serios equivale a una que no tiene chance raisonnable de succès ${ }^{107}$.

Visto desde los propósitos que los recursos en general buscan cumplir, rechazar preliminarmente un recurso sin expectativas de éxito aparece justificado porque vuelve innecesaria la intervención del tribunal superior. Dado que el propósito (legítimo) de los recursos es corregir errores ${ }^{108}$, un recurso que sí tiene expectativas de éxito sería aquel que denuncia un error real y convoca seriamente al tribunal superior para corregirlo. Pero, a la inversa, un recurso que no tiene expectativas de éxito sería aquel en que a primera vista se nota que no hay error alguno que el tribunal superior necesite corregir.

Aquí también cabe una relectura desde la buena fe procesal. El litigante que interpone un recurso siempre lo hace teniendo algún incentivo, motivo o propósito. El propósito que el litigante de buena fe tiene en mente es que se corrija (lo que él cree es) un error. Pero si su recurso evidentemente carece de expectativas de éxito -al punto que el propio litigante debería haberlo notado desde un comienzo- ¿entonces con qué otro propósito interpuso el recurso?

Como sabemos, corregir un error no es el único propósito que un litigante puede tener. El propósito que tiene en mente un litigante de mala fe, en cambio, es dilatar el procedimiento, incrementar los costos de la contraparte o postergar el cumplimiento de la sentencia, entre otros. También podría suceder que si los honorarios del abogado están fijados por el número de sus gestiones judiciales (y no por el éxito de cada gestión) el abogado tendría un incentivo para interponer recursos, a pesar de estar manifiestamente infundados, para cobrar más honorarios a su cliente. Al filtrar casos por manifiesta falta de fundamento, por lo tanto, indirectamente se filtra según la buena o mala fe en los propósitos para interponer recursos. Si el recurso manifiestamente no tiene expectativas reales de éxito -i.e., evidentemente no hay un error que corregir, que habría sido el propósito del litigante de buena fe- no queda sino entender que el litigante interpuso el recurso teniendo en mente alguno de los otros propósitos que, por el contrario, son los propios del litigante de mala fe.

\section{VOTACIÓN POR UNANIMIDAD}

En la casación en el fondo civil chilena existe una regla especial de votación por unanimidad de la Corte Suprema para ejercer el rechazo por manifiesta falta de fundamento. En la apelación intermedia ante las cortes federales de apelación de Estados Unidos también existe una regla especial de unanimidad por apelación frívola. En la casación francesa e italiana el rechazo preliminar del filtro también se toma por unanimidad, pero no en virtud de una regla especial. En Francia e Italia la regla general (que también aplica a sus filtros) es que las deliberaciones en estos tribunales son anónimas y la sentencia se dictan a nombre del tribunal como un todo, como si fuesen unánimes, omitiendo cualquier voto disidente ${ }^{109}$.

\footnotetext{
106 Martineau (1984) p. 850.

107 BufFet (2005) p. 108.

108 Uzelac \& van Rhee (2014) p. 3; Kodek (2014) p. 36; Shapiro (1980) p. 629.

109 Para Francia, Troper y Grzegorczyk (1997) pp. 110, 122. Para Italia, Taruffo y La Torre (1997) p. 148.
} 
Desde el punto de vista de un supuesto derecho a recurso, esta regla de unanimidad es vista como una garantía del recurrente. Si acceder al recurso es un derecho, entonces la regla de unanimidad para el rechazo preliminar resulta necesaria porque solo un superquorum del tribunal tendría legitimidad suficiente para restringir ese derecho del litigante. Desde la perspectiva de la buena fe procesal, en cambio, el filtro de manifiesta falta de fundamento y la regla de unanimidad aparecen, en realidad, como dos caras de la misma moneda. Releída como este estándar de conocimiento del Derecho común a todos los profesionales del Derecho, sería de esperar que ante una falta de fundamento "manifiesta" todos los jueces tengan la misma opinión. A la inversa, si la falta de fundamento no resulta manifiesta para todos los jueces del tribunal, eso implica por definición que la falta de fundamento no es realmente "manifiesta" en primer lugar. Por lo tanto, el rechazo por manifiesta falta de fundamento no puede sino ser ejercido mediante unanimidad entre los jueces porque el criterio mismo del filtro -i.e., manifiestamente infundado a la vista de todos- "es" esa unanimidad.

\section{NO CONTRADECIR LA JURISPRUDENCIA}

Otra idea que se repite al examinar el Derecho comparado es que el criterio del filtro implica excluir aquellos recursos cuyos argumentos contradicen una jurisprudencia asentada. En el caso de las cortes federales de apelación de Estados Unidos ${ }^{110}$, por ejemplo, entender el criterio del filtro de esta forma resulta consistente con su tradición jurídica de common law. Ahí donde los precedentes judiciales son jurídicamente vinculantes, un recurso cuyo fundamento contradice tales precedentes es, en sí mismo, un fundamento contrario a Derecho.

El mismo criterio de "no contradicción de la jurisprudencia" se repite en Italia y Chile ${ }^{111}$. Pero a la inversa de Estados Unidos, la inclusión del mismo criterio en estas dos jurisdicciones aparece en principio contradictorio con la tradición jurídica. A diferencia del common law, como sabemos, en la tradición jurídica romanista los fallos judiciales anteriores no cuentan como una fuente formal del Derecho. Por lo tanto, un recurso cuyo fundamento contradice fallos anteriores no sería aquí contrario a Derecho. ¿Por qué debería considerarse como manifiestamente infundado un recurso contrario a la jurisprudencia si, en rigor, sus fundamentos no van en contra de ninguna de las fuentes formales del Derecho dentro de esa tradición jurídica?

Esta aparente contradicción con la tradición jurídica romanista puede ser resuelta gracias a la relectura desde la buena fe procesal. Según la visión ortodoxa, los jueces de civil law justifican sus decisiones no en base a fallos judiciales sobre casos anteriores (precedentes) sino que aplicando la legislación vigente a casos actuales. Aún así los fallos anteriores son ejemplos acerca de cómo otros jueces han aplicado la misma legislación ${ }^{112}$. Por lo tanto, que el recurso contradiga gran parte de, sino todos, esos ejemplos anteriores es más bien un "indicador" de que la aplicación de la legislación propuesta ahora por el recurrente ha sido ya muchas veces juzgada como infundada.

110 Martineau (1984) p. 851.

111 En Italia, Codice d Procedura Civile, Art. 360bis (1). En Chile, Romero et al. (2008) p. 232.

112 Del Rio (2015a) p. 487. 
Así visto, incluir en la manifiesta falta de fundamento la no contradicción de la jurisprudencia no sería más que la continuación del requisito anterior de votación por unanimidad entre los jueces, pero ahora a un nivel intergeneracional. Entendido como un estándar de conocimiento del Derecho que aplica para todos, la falta de fundamento podría resultar manifiesta no solo para los jueces actuales del tribunal, sino que también para sus jueces antecesores. Por lo tanto, los recursos que contradicen la jurisprudencia son excluidos por manifiesta falta de fundamento no porque contradecir la jurisprudencia sea un argumento contrario a Derecho per se. No, excluir recursos que contradicen la jurisprudencia es un criterio de filtro incluso dentro del civil law más bien porque ir en contra de la jurisprudencia es un "síntoma" de que la falta de fundamento resulta manifiesta incluso para la unanimidad intergeneracional de los jueces.

\section{FUNDAMENTACIÓN ABREVIADA}

Otro elemento común en la regulación del filtro en estas jurisdicciones es que el rechazo por manifiesta falta de fundamento o sus equivalentes se realiza mediante una sentencia con requisitos simplificados de fundamentación. Algunos autores suelen criticar esta medida porque infringiría el derecho a una sentencia motivada ${ }^{113}$. Visto como una solución a la sobrecarga, esta fundamentación abreviada se justificaría porque de lo contrario -i.e., exigirse una fundamentación detallada para cada rechazo preliminar- se frustraría el propósito del filtro. El tribunal no lograría ahorrar carga de trabajo si la fundamentación del rechazo preliminar mismo consume gran parte de la capacidad de trabajo del tribunal ${ }^{114}$.

Desde la perspectiva de la buena fe procesal, sin embargo, la fundamentación abreviada tiene una justificación más simple. Si la falta de fundamento es "manifiesta" al punto que debería resultar prima facie evidente para todos -i.e., no solo para los jueces, sino que también para el propio recurrente y para la comunidad jurídica en general- entonces una fundamentación detallada resulta redundante. Los jueces no necesitan explicar detalladamente al recurrente cuál fue su error argumentativo obvio, error que el recurrente mismo ya sabe o debería haber sabido desde un comienzo. Para el resto de la comunidad jurídica tampoco. El tribunal no necesita explicar detalladamente cuál fue el error argumentativo en que incurrió el recurrente si se trata de un error tan manifiesto que el resto de la comunidad jurídica también lo notaría a primera vista.

\section{7. ¿Discrecionalidad?}

Una cuestión más disputada en el Derecho comparado es el carácter discrecional de este tipo de filtro. En un extremo se encuentra Francia, donde autores como Ferrand niegan que este tipo de filtro implique algún grado de discrecionalidad ${ }^{115}$. En el otro extremo se encuentra Chile, donde la Corte Suprema señaló que el filtro de manifiesta falta de fundamento implicaría una verdadera discrecionalidad para seleccionar casos ${ }^{116}$. Y en un punto

113 En Francia, por ejemplo, Flauss (2005) pp. 43-50; Boré y Boré (2015) p. 657.

114 Galic (2014) pp. 159-174.

115 Ferrand (2017) p. 196.

116 Corte Suprema Chilena (2013) p. 11. 
intermedio estaría Italia, donde según autores como Taruffo su filtro de la casación implica algún grado de discrecionalidad, pero no al nivel del writ of certiorari estadounidense ${ }^{117}$.

Desde la perspectiva de la buena fe procesal, esta disputa sobre la discrecionalidad presenta dos lados. Por una parte, los criterios para ejercer este tipo de filtro están formulados en base a conceptos abiertos que, como vimos, no permitirían una definición más que agregar sinónimos o antónimos. Claro, esa indefinición del criterio de filtro implicaría aparentemente algún grado de discrecionalidad. Un concepto abierto puede ser llenado por los distintos jueces con distintas concepciones específicas. Una facultad discrecional implica, por definición, que los jueces que la ejercen pueden tener legítimamente dos o más opiniones acerca de cómo ejercer esa facultad.

Pero, por otra parte, el criterio mismo de este tipo de filtro pareciera negar tal discrecionalidad. Cuando se trata de una falta de fundamento "manifiesta" entonces no debería haber dos o más opiniones sobre ella. Definido como un error argumentativo evidente prima facie para todos, ante una falta de fundamentación así de manifiesta los jueces deberían tener una y la misma opinión acerca de cómo ejercer su facultad de rechazo preliminar. Esa es, como vimos, la razón por la cual este filtro se ejerce en base a una regla de votación por unanimidad. Si para ejercer esta facultad pudiera haber, legítimamente, diferencias de opiniones entre los jueces, entonces esta facultad no estaría siendo ejercida a casos realmente manifiestos para todos. En suma, este filtro no debería ser entendido como una facultad discrecional porque su criterio de aplicación alude precisamente a aquellos casos donde esas diferencias de opinión no deberían existir.

\section{CONCLUSIÓN: CONTRA-ARGUMENTOS}

A modo de conclusión, demos respuesta a tres posibles contraargumentos a esta relectura ${ }^{118}$. Primero, se podría argumentar que un recurso manifiestamente infundado no necesariamente se debe a mala fe, sino que a simple "sesgo del perdedor". Esto es, el litigante derrotado tiende a confundir una sentencia desfavorable con un error del tribunal. Así, el litigante perdedor intentaría recursos manifiestamente infundados porque, nublado por ese sesgo, pierde autocrítica. Pero el sesgo del perdedor aplica para la parte misma, no para el abogado que la representa. Aún cuando el cliente se resista a aceptar una sentencia desfavorable, es el rol de su abogado saber filtrar a su vez las demandas del cliente que tienen o no algún mérito jurídico. Si el abogado va a ejecutar la voluntad del cliente, sea cual sea su mérito, ¿entonces qué sentido tendría el patrocinio de abogados en primer lugar? El sesgo del perdedor justificaría los recursos manifiestamente infundados si está permitido interponer recursos sin representación de abogado (litigación pro se). Las personas legas no tienen por qué saber distinguir entre argumentos manifiestamente fundados o infundados jurídicamente precisamente porque no son profesionales del Derecho. Pero ahí donde el patrocinio de abogado sí es obligatorio -como en la casación chilena, francesa e italiana- el sesgo del perdedor no es justificación. Si un abogado no filtra las pretensiones infundadas

117 Comoglio et al. (2011) p. 721; Taruffo (2011) p. 31.

118 Por ejemplo, Delgado (2017) p. 109. 
de su cliente, entonces el abogado actúa de mala fe al interponer un recurso a sabiendas que no tenía mérito alguno.

Un segundo contra argumento podría ser que para los abogados predecir cuándo el tribunal rechazará un recurso por manifiesta falta de fundamento es bastante más incierto de lo que parece. Como vimos anteriormente, esta dificultad no puede provenir de la (in) definición del criterio de filtro mismo. Entre profesionales del Derecho no es necesario aclarar aún más qué cuenta como "manifiestamente infundado" porque es de suponer que, en cuanto profesionales, ellos ya saben cuáles son los conceptos y reglas básicas de argumentación que deben ser respetadas dentro del Derecho. Pero si un abogado aún así reiteradamente no puede hacer la distinción entre argumento (manifiestamente) fundado o infundado entonces cabe cuestionarse si ese abogado posee realmente o no el piso común de conocimientos necesarios para participar en el proceso judicial. Esto no niega que existan algunos casos difíciles, esto es, casos donde dos profesionales competentes pueden tener legítimamente argumentos contradictorios. Pero sí niega que todos o la mayoría de los casos puedan ser vistos como difíciles. Si para un abogado la mayoría de los casos le parecen tener argumentos contradictorios legítimos -esto es, la mayoría de los casos le parecen, en este sentido, difíciles- entonces nuevamente cabe cuestionar si ese abogado posee las competencias jurídicas mínimas para litigar ante los tribunales superiores. Un profesional también es responsable por saber cuáles son los límites de su conocimiento y, en consecuencia, abstenerse de participar en las áreas que no domina. De este modo, un abogado que interpone recursos careciendo del piso común de conocimientos también actúa de mala fe. Su mala fe no radica en que sepa que los recursos que interpone carecen de mérito (ahí radica precisamente su ignorancia) sino porque "sabe que no sabe" y debería haber delegado el caso a un colega competente en esa área.

Un tercer contra argumento sería que la dificultad provenga no de los abogados, sino que de los jueces. Pero esta explicación estaría resuelta por la regla de votación por unanimidad. La probabilidad de que varios jueces se equivoquen al mismo tiempo y en la misma dirección, si bien nunca deja de existir matemáticamente, se reduce a mayor cantidad de jueces ${ }^{119}$. Una variante más plausible de este contra argumento es que, en realidad, el tribunal tenga un problema de sobrecarga. El filtro se volvería menos predecible porque los jueces, concertadamente, rechazarían preliminarmente más recursos que solo los manifiestamente infundados para aliviar así su exceso de carga. La sobrecarga de los tribunales es, sin duda, un problema que aqueja a muchas jurisdicciones. Pero si la sobrecarga es el verdadero problema de fondo -como es claramente el caso de la casación italiana ${ }^{120}$, y la apelación en EE.UU. ${ }^{121}$ - ese problema también sobrepasaría cualquier discusión dogmática que podamos tener acerca de qué significa "manifiesta falta de fundamento". Un tribunal sobrecargado distorsiona el uso de las reglas procesales que lo rigen, sea como sea que esas reglas estén formuladas y sea como sea que los académicos digan que esas reglas deban ser entendidas. Pero si tal problema de sobrecarga no existe -como sería, según algunos, la si-

19 Kodek (2014) p. 43.

120 Comiglio et al. (2011) p. 709; Ferraris (2015) pp. 156-159.

121 RASCH (2009) p. 267. 
tuación de la Corte Suprema chilena ${ }^{122}$, y la casación francesa ${ }^{123}$ - entonces no habría razón para sospechar que tribunales que están en condiciones relativamente buenas para trabajar hagan un uso distorsionado de este filtro.

\section{BIBLIOGRAFÍA CITADA}

Amoroso, Giovanni (2012): Il giudizio civile di casssazione (Milano, Giuffrè editore).

Amrani-Mekki, Soraya (2005): "Les textes organisant la non-admission des pourvois en cassation en droit français", en Amrani Mekri, Soraya y Cadiet, Loïc (edits.), La Sélection des Pourvois à la Cour de Cassation (París, Economica) pp. 19-31.

AmRANI-MeKKI, Soraya (2014): "L'accès aux cours suprêmes: rapport français", en WARSAW Conference, The functions of the Supreme Court - issues of process and administration of justice. (Varsovia, Polonia) pp. 1-12. Disponible en: colloquium2014.uw.edu.pl/wpcontent/uploads/sites/21/2014/06/AMRANI_MEKKI_L\%E2\%80\%99ACCES-AUXCOURS-SUPREMES-final.pdf. Fecha de consulta: 13 de noviembre del 2018.

Andrews, Neils (2014): "Restrictions on Appeals in English Law", en Uzelac, Alan y van RHeE, C.H. (edits.), Nobody's Perfect. Comparative Essays on Appeals and other Means of Recourse against Judicial Decisions in Civil Matters. (Cambridge, Intersentia) pp. 73-94.

Andrews, Neils (2017): “The Supreme Court of the United Kingdom: A Selective Tribunal with the Final Say in Most Matters", en van RHeE, C.H. y Fu, Yulin (edits.), Supreme Courts in China and in the Western: Adjudication at the Service of Public Goals (Cham: Suiza, Springer) pp. 37-52.

ATriA, Fernando (2005): "Proceso civil. La casación como problema", Revista de Derecho de la Universidad Adolfo Ibañez, No 2: pp. 249-353.

Plant, Charles (2004): Blackstone's Civil Practice (Oxford, Oxford University Press).

Blake, Charles y Drewry, Gavin (2004): "The Role of the Court of Appeal in England and Wales as an Intermediate Court", en LE Sueur, Andrew (edit.), Building the UK's New Supreme Court. National and Comparative Perspective. (Oxford, Oxford University Press) pp. 221-236.

Bogdan, Michael (2013): Concise Introduction to Comparative Law (Groningen, Países Bajos, Europa Law Publishing).

Boré, Jacques y Boré, Louis (2015): La cassation en matèrie civile (París, Dalloz, quinta edición).

Bowie, Jennifer, Songer, Donald y Szmer, John (2014): The View From the Bench and Chambers: examining judicial process and decision making on the U.S. Courts of Appeals (Charlottesville, University of Virginia Press).

BufFET, Jean (2005): "Le critère de la non-admission: quelle rationalité ?", en AMrANiMekri, Soraya y Cadiet, Loïc (edits.), La Sélection des Pourvois à la Cour de Cassation (París, Economica) pp. 103-109.

122 Tavolari (2014) p. 114; Rojas (2014) pp. 33-35; Delgado (2017) p. 115.

123 Ferrand (2017) pp. 176-186. 
Cappelletti, Mauro (1989): The Judicial Process in Comparative Perspective. (New York, Clarendon University Press).

Castanias, Gregory A. y Klonoff, Robert H. (2008): Federal Appellate Practice and Procedure (St. Paul, Thomson West).

Coccia, Alessandro (2015): "Storia e Struttura della Corte di Cassazione", en Levita, Luigi (edit.); Il Ricorso Per Cassazione. La Nuova disciplina del giudizio di legittimità (Matelica, Nuova Giuridica) p. 13-33.

Collados, Eugenio (2005): El rechazo del recurso de casación por manifesta falta de fundamento. Memoria de prueba para optar al Grado de Licenciado en Ciencias Jurídicas y Sociales de la Universidad de Chile. Disponible en: http://repositorio.uchile.cl/handle/2250/114499

Corte Suprema Chilena (2013), Informe Proyecto de Ley 7-2012 "[Q]ue establece Nuevo Código Procesal Civil” (Oficio No 24-2013, Boletín No 8197-07).

Corte Suprema di Cassazione (2013): Tabella di Organizzazione. Disponible en: www. cortedicassazione.it/cassazione-resources/resources/cms/documents/Tabella_di_organizzazione.pdf. Fecha de consulta: 13 de noviembre del 2018.

Comoglio, Luigi, Corrado, Ferri, Taruffo, Michele (2011): Lezioni sul processo civile. I. Il Proceso ordinario di cognizione (Bologna, Il Mulino, quinta edición)

Cross, Frank B. (2007): Decision Making in the U.S. Courts of Appeals (Stanford, Stanford University Press).

Del Río, Carlos (2015a): "Casación Civil: El desafío de la correcta racionalización y Iurisprudencia Novit Curia en una futura reforma legal", Revista Chilena de Derecho, vol. XLII, No 2: pp. 483-513.

Del Río, Carlos (2015b): "Motivo de casación en el fondo civil en Chile: Problemas y perspectivas de reforma en Chile", Revista Ius et Praxis, vol. XXI, No 1: pp. 161-198.

Delgado, Jordi (2017): "La casación civil en el fondo: Un último intento para no cantarle un requiem”, en Palomo, Diego, Delgado, Jordi y Núñez, Raúl (edits.), Recursos Procesales. Problemas Actuales (Santiago, Der Ediciones) pp. 107-135,

Domej, Tanja (2014): "What is an important case? Admissibility of Appeals to the Supreme Courts in the German-Speaking Jurisdictions", en Uzelac, Alan y Van Rhee, C.H. (edits.), Nobody's Perfect. Comparative Essays on Appeals and other Means of Recourse against Judicial Decisions in Civil Matters (Cambridge, Intersentia) pp. 277-290.

Drago, Guillaume, Fauvarque-Cosson, Bénédicte y Goré, Marie (2015): L'accès au juge de cassation. Colloque du 15 juin 2015. (París, Société de Législation Comparée).

Drewry, Gavin, Blom-Cooper, Louis y Blake, Charles (2007): The Court of Appeal (Oxford: Hart Publishing).

Drewry, Gavin y Blom-Cooper, Louis (2009): "The House of Lords and the English Court of Appeal”, en Blom-Cooper, Louis Jacques, Dickson, Brice y Drewry, Gavin (edits.), The Judicial House of Lords 1876-2009 (Oxford, Oxford University Press) pp. 48-63.

FERRAND, Frédérique (2015): "La juridiction judiciaire suprême en droit comparé: missions, filtrage, intensité du contrôle”, en Drago, Guillaume, Fauvarque-Cosson, 
Bénédicte y Goré, Marie (edit.), L’accès au juge de cassation. Colloque du 15 juin 2015 (París, Société de Législation Comparée) pp. 147-218.

Ferrand, Frédérique (2017): “The French Court of Cassation: On The Threshold of a Quiet Revolution?”, en van Rhee, C.H. y Fu, Yulin (edits.), Supreme Courts in China and in the Western: Adjudication at the Service of Public Goals (Cham, Suiza, Springer) pp. 175-206.

FerRaRIS, Federico (2015): Rationing Justice. La selezione dei ricorsi nelle Corti Supreme di Stati Uniti e Italia (Torino, G. Giappichelli Editore).

Ferreres Comella, Víctor (2004): "The European Model of Constitutional Review of Legislation: Toward decentralization", International Journal of Constitutional Law, vol. II, No 3: pp. 461-491.

Figueroa, Juan y Morgado, Erika (2014): Recursos procesales civiles y cosa juzgada (Santiago, Thomson Reuters).

FInCK, Danielle E. (1992): "Judicial Review: The United States Supreme Court Versus the German Constitutional Court", Boston College International and Comparative Law Review, vol. XX, No 1: pp. 123-158.

Flauss, Jean-François (2005): "La selection des recours et la Convention européene des droits de l'homma”, en Amrani-Mekri, Soraya y Cadiet, Loïc (edits.), La Sélection des Pourvois à la Cour de Cassation (París, Economica) pp. 43-50.

Galic, Ales (2014): "Does a Decision of the Supreme Court Denying Leave to Appeal Need to Contain Reasons?", en Adolphsen, Jens et al. (edits.), Festschrift für Peter Gottwald zum 70. Geburtstag (München, C.H. Beck) pp. 159-174.

Geeroms, Sophie M.F. (2002): "Comparative Law and Legal Translation: Why the Terms Cassation, Revision and Appeal Should Not Be Translated...”, American Journal of Comparative Law, vol. L, No 1: pp. 201-228.

Gorigoitía, Felipe (2008): "La buena fe en el proceso civil chileno", Nomos (Universidad de Viña del Mar), No 2: pp. 133-159.

Gorigoitía, Felipe (2015): "La inadmisión como técnica multipropósito. Un análisis desde los recursos civiles en España y Chile”, Revista Opinión Jurídica (Universidad de Medellín), vol. XIV, No 28: pp. 197-214.

Guarnieri, Carlo y Pederzoli, Patrizia (2002): The Power of the Judges. A comparative study of courts and democracy (Oxford, Oxford University Press).

Hooper, Laura, Miletich, Dean and Levy, Angelia (2011): Case Managment Procedures in the Federal Courts of Appeals. (Estados Unidos, Federal Judicial Center, segunda edición). Disponible en: https:/www.fjc.gov/sites/default/files/2012/CaseMan2.pdf. Fecha de consulta: 13 de noviembre del 2018.

Hunter, Iván (2009): "El poder del juez para rechazar in limine la demanda por manifiesta falta de fundamento", Revista Ius et Praxis, vol. XV, No 2: pp. 117-163.

Israel, Ruth (2006): "Control de Admisbilidad del Recurso de Casación en Materia Civil, Años 2000-2004”, REJ - Revista de Estudios de la Justicia, No 8: pp. 191-203.

Jolowicz, John Anthony (2000): On Civil Procedure (Cambridge, Cambridge University Press). 
KodeK, Georg. E. (2014): "Appellate Proceedings in Civil Cases - Traditional Remedies in Light of Contemporary Problems", en Uzelac, Alan y Van Rhee, C.H. (edits.), Nobody's Perfect. Comparative Essays on Appeals and other Means of Recourse against Judicial Decisions in Civil Matters (Cambridge, Intersentia) pp. 35-52.

Kravitz, Mark R. (2002): "Unpleasant Duties: Imposing Sanctions for Frivolous Appeals", The Journal of Appellate Process and Practice, vol. IV, No 2: pp. 335-348.

Lamanda, Vincent (2010): "Préface", en Weber, Jean-François, La Cour de Cassation (Paris, La documentation française) pp. 7-9.

Larroucau, Jorge (2013): "Tres lecturas de la buena fe procesal", Revista Chilena de Derecho Privado, No 21: pp. 259-305.

LARroucau, Jorge (2017a): "Adiós a la fojas. Reglas procesales, autos acordados y tramitación electrónica en Chile", Revista de Derecho Privado (Universidad Externado de Colombia), No 33: pp. 195-234.

Larroucau, Jorge (2017b): “El filtro de lo 'manifiestamente improcedente' según la Corte Suprema”, en Acuña, Marcela y Del Picó, Jorge (edits.), Estudios de Derecho Familiar (Talca, Editorial Universidad de Talca) pp. 441-456.

Le Sueur, Andrew y Cornes, Richard (2001): The Future of the United Kingdom Highest Courts (Londres, The Constitution Unit). Disponible en: www.ucl.ac.uk/spp/publications/unit-publications/76.pdf. Fecha de consulta 13 de noviembre del 2018.

Libedinsky, Marcos (1995): "La manifiesta falta de fundamento en el recurso de casación en el fondo", Revista Gaceta Jurídica, No 183: pp. 7-11.

MaCiOCE, Luigi (2015): “Il 'filtro' per l'accesso al giudizio di legittimità”, en ACIERno, María, Curzio, Pietro y Giusti, Alberto (edits.), La Cassazione Civile. Lezioni dei magistrati della Corte Suprema Italiana (Bari, Cacucci Editore, novena edición) pp. 385-395.

MaK, Elaine (2013): Judicial Decision-Making in a Globalised World: A Comparative Analysis of the Changing Practices of Western Highest Courts (Oxford, Hart Publishing, 2013.

Marcus, Richard (2014): "Appellate Review in the Reactive Model: The Example of The American Federal Courts", en Uzelac, Alan y van Rhee, C.H. (edits.), Nobody's Perfect. Comparative Essays on Appeals and other Means of Recourse against Judicial Decisions in Civil Matters (Cambridge, Intersentia) pp. 105-126.

Martineau, Robert J. (1984): “Frivolous Appeals: The Uncertain Federal Response”, Duke Law Journal, vol. MCMLXXXIV, No 5: pp. 845-886.

Mosquera, Mario y Maturana, Cristián (2010): Los recursos procesales (Santiago, Editorial Jurídica de Chile).

Muñoz, Sergio (2010): "Presente y futuro de la casación civil en Chile”, en Tavolari, Raúl (edit.), Derecho Procesal Contemporáneo, Tomo I (Santiago, PuntoLex) pp. 90-182.

Norkus, Rimvydas (2015): “The Filtering of Appeals to the Supreme Courts", en Network of the Presidents of the Supreme Judicial Courts of the European Union, Dublin Conference, pp. 1-16. Disponible en: https:/www.lat.lt/data/public/ uploads/2018/01/introductory-report-the-filtering-of-appeals-to-supreme-courts-president-rimvydas-norkus.pdf. Fecha de consulta 18 de noviembre del 2018.

Nowak, John E. y Rotunda, Ronald D. (2004): Constitutional Law (St. Paul, Minnesota, Thomson West, séptima edición). 
Núñez Ojeda, Raúl y Pérez-Ragone, Álvaro (2015): Manual de Derecho Procesal Civil. Los Medios de Impugnación (Santiago, Thomson Reuters).

O’Connor, Sandra (1984): "Our Judicial Federalism”, Case Western Reserve Law Review, vol. XXXV, No 1: pp. 1-12.

Oldfather, Chad (2010): "Error Correction". Indiana Law Journal, vol. LXXXV, No 1: pp. 49-85.

Palomo, Diego (2016): "Séptima parte. El recurso de casación en el fondo", en Bordalí, Andrés, Cortez, Gonzalo y Palomo, Diego (edits.), Proceso civil: Los recursos y otros medios de impugnación (Santiago, Thomson Reuters) pp. 295-362.

Perdriau, André (1994): "Les formations restreintes de la Cour de cassation", La Semaine Juridique No 23: pp. 273-284.

Piedrabuena, Guillerno (1996): Reflexiones sobre la casación después de las modificaciones de la Ley 19.374 (Santiago, Fallos del Mes).

Provine, Dories Marie (1980): Case selection in the United States Supreme Court (Chicago, University of Chicago Press).

Rasch, Meehan (2009): "Not Taking Frivolity Lightly: Circuit Variance in Determining Frivolous Appeals under Federal Rule of Appellate Procedure 38”, Arkansas Law Review, vol. LXIX, No 249: pp. 249-285.

Rehnquist, William H. (2002): The Supreme Court (New York, Vintage).

Richman, William M., y ReYnolds, William L. (1996): "Elitism, Expediency and the New Certiorari: Requiem for the Learned Hand Tradition", Cornell Law Review, vol. LXXXI, No 1: pp. 273-342.

Richman, William M. y Reynolds, William L. (2013): Injustice on Appeal. The United States Courts of Appeals in Crisis (Oxford, Oxford University Press).

Rogowski, Ralf y Gawron, Thomas (2016): "Constitutional Litigation as Dispute Processing. Comparing the U.S. supreme Court and the German Federal Constitutional Court", en Rogowski, Ralf y Gawron, Thomas (edits.), Constitutional courts in comparison: the U.S. Supreme Court and the German Federal Constitutional Court (New York, Berghahn Books, segunda edición) pp. 1-22.

Rojas, Mario (2014): "En defensa de la casación”, Revista Actualidad Jurídica (Universidad del Desarrollo), No 29: pp. 25-42.

Romero, Alejandro, Aguirrezabal, Maite y Baraona, Jorge (2008): "Revisión crítica de la causal fundante del recurso de casación en el fondo en materia civil", Revista Ius et Praxis, vol. XIV, No 1: pp. 225-259.

Romero, Alejandro (2013): El recurso de casación en el fondo civil. Propuestas para la generación de precedentes judiciales (Santiago, Thomson Reuters).

Shapiro, Martin M. (1980): "Appeals", Law and Society Review, vol. XIV, No 3: pp. 629-661.

Silvestri, Elizabetta (2011): “Corti Supreme Europee: Accesso, Filtri e Selezione”, en Centro Studi Giuridici e Politici y Centro Internazionale Magistrati (edits.), Le Corti Supreme. Atti del Convengno (Milano, Giuffrè) pp. 105-116.

Taruffo, Michele (2001): "Le Corti Supreme Europee: Acceso, Filtri, Selezione", en Centro Studi Giuridici e Politici y Centro Internazionale Magistrati (edits.), Le Corti Supreme. Atti del Convengno (Milano, Giuffrè) pp. 95-104. 
Taruffo, Michele (2011): "Le funzioni delle Corti Supreme. Cenni generali", Annuario di Diritto Comparato e di Studi Legislativi, vol. MMXI: pp. 11-36.

Taruffo, Michele y La Torre, Massimo (1997): "Precedent in Italy", en MacCormick, Neil y Summers, Robert S. (edits.), Interpreting Precedents. (Aldershot [etc.], Ashgate/ Darthmouth) pp. 141-188.

TaVolari, Raúl (1996): Nuevo régimen de los recursos de casación y queja (Santiago, Conosur).

TAVOlari, Raúl (2014): "La eliminación de la casación civil: marchando contra los tiempos. (Una propuestas de conciliación)”, Revista Actualidad Jurídica (Universidad del Desarrollo), No 29: pp. 83-100.

Troper, Michel y Grzegorczyk, Christophe (1997): "Precedent in France", en MacCorMick, Neil y Summers, Robert S. (edits.), Interpreting Precedents. (Aldershot [etc.], Ashgate/Darthmouth) pp. 103-140.

Uzelac, Alan y van Rhee, C.H. (2014): "Appeals and Other Means of Recourse Against Judgments in the Context of the Effective Protection of Civil Rights and Obligations", en Uzelac, Alan y van Rhee, C.H. (edits.), Nobody's Perfect. Comparative Essays on Appeals and other Means of Recourse against Judicial Decisions in Civil Matters. (Cambridge, Intersentia) pp. 3-13.

VigneAU, Vincent (2010): "Le régime de la non-admission des pourvois devant la Cour de cassation”, Recueil Dalloz, vol. II: pp. 102-112.

Weber, Jean-François (2010): La Cour de Cassation (Paris, La documentation française).

WheELER, Russel R. (2004): "Intermediate Courts of Appeals and Their Relations with Top-level Courts: The US Federal Judicial Experience”, en Le Sueur, Andrew (edit.), Building the UK's New Supreme Court. National and Comparative Perspective (Oxford, Oxford University Press) pp. 237-270.

Wijffels Alain (2013): "France from the Revolution to the Present", en Wijffels, A.A. y Van Rhee, C.H. (edits.), European Supreme Courts. A Portrait through History (Londres, Third Millenium Publishing) pp. 14-37.

Zuckerman, Adrian (2013): Zuckerman on Civil Procedure (Londres, Thomson/Sweet \& Maxwell, tercera edición).

Zweigert, Konrad y Kötz, Hein (1998): Introduction to Comparative Law (trad. Tony Weir, Oxford, Clarendon Press).

\section{NORMAS CITADAS}

1. ChILE

Código de Procedimiento Civil (30/08/1902): Art. 782.

Código del Trabajo (29/03/2008): Art. 480 inc. 5o.

Código Procesal Penal (12/10/2000): Art. 383 inc. 2o; Art. 475, inc. $3^{\circ}$.

Ley No 19.968 (25/08/2004), Crea los Tribunales de Familia: Art. 67.

Ley No 20.866 (14/14/2015), Modifica el Código de Procedimiento Civil para Establecer la Tramitación Digital de los Procedimientos Judiciales: Art. 5. 
2. ESPAÑA

Ley de Enjuciamiento Civil (3/2/1881): Art. 1710 (3).

3. FRANCIA

Code de l'organisation judiciaire (8/6/2006): Art. L431-1; Art. 131-6.

Code de procédure CIVILE (5/12/1975): Art. 1014.

4. ITALIA

Costituzione della Republica Italiana (22/12/1947): Art. 111.

Ordinamiento Giudiciario (30/1/1941): Art. 65; Art. 67.

Codice di Procedura Civile (28/10/29140): Art. 360 bis.

5. EsTAdOS UNIDOS

Federal Rules of Appellate Procedure (4/12/1967): Title VII, Rule 34 (2); Rule 36.

6. INGLATERRA

Practice Direction 52C (21/12/2017), Appeals to the Court of Appeals: Rule 15(1).

Civil Procedure Rules (10/12/1998): Rule 52.3 (4); Rule 52.3(6); Rule 52.11(3).

\section{JURISPRUDENCIA CITADA}

LABBÉ CON REYES (2011): Corte Suprema (Cuarta Sala), 22 de Julio del 2011. Rol No 6.065-09.

Matamala Walter, Olga Graciela con Corpbanca (2007): Corte Suprema (Primera Sala), 29 de mayo del 2007. Rol No 4.200-05.

URTubia con Inmobiliaria Quillay (2014): Corte Suprema (Primera Sala), 8 de Julio del 2014, Rol No 10.813-14.

DEL INCA CON UGALDE (2010): Corte Suprema (Primera Sala), 17 de Agosto del 2010. Rol No 5.336-10.

Millar con Inmobiliaria LiRCay (2014): Corte Suprema (Cuarta Sala), 6 de Agosto del 2014. Rol No 11.353-14.

SCHWARSENBERG CON SCHWARSENBERG (2010): Corte Suprema (Primera Sala), 27 de Julio del 2010. Rol No 4.852-10.

IbarRa CON ARAVENa (2010): Corte Suprema (Primera Sala), 3 de Agosto del 2010. Rol No 4.939-10.

CONTROL DE CONSTITUCIONALIDAD SOBRE PROYECTO DE LEY SOBRE COMPOSICIÓN, ORGANIZACIÓN Y ATRIBUCIONES DE LA CORTE SUPREMA Y MODIFICACIONES A LOS RECURSOS DE QUEJA Y DE CASACIÓN (1995): Tribunal Constitucional chileno, Rol No 205, 1 de febrero de 1995.

Regina v. Secretary of State For Trade and Industry Ex Parte Eastaway [2000] 1 All ER 27 (HL).

SWAIN V. HILLMAN [1999] EWCA, para. 7. 